AJChE 2020, Vol. 20, No. 1, 88 - 98

Experimental and Numerical Investigations of Fluid Flow Behaviors in a Biomass Cyclone Burner

\title{
Pasymi *1
}

Yogi Wibisono Budhi ${ }^{2}$

Yazid Bindar ${ }^{2}$

${ }^{1}$ Departement of Chemical Engineering, Faculty of Industrial Technology, Universitas Bung Hatta, Padang, Indonesia

${ }^{2}$ Energy and Processing System Research Group, Study Programmes of Chemical, Bioenergy and Chemurgy Engineerings, Faculty of Industrial Technology, Institut Teknologi Bandung, Indonesia

`e-mail: pasymi@bunghatta.ac.id

A combination of the experimental and numerical methods was used to investigate the fluid flow behaviors in a proposed cyclone burner. Recirculation flow and pressure drop, two of the important fluid flow behaviors that affect the burner's performance, have been studied here. Experimentally, the recirculation flow phenomenon in the burner was observed through paper slices dynamic in a transparent burner, and pressure drop was measured using a tube manometer. Meanwhile numerically, the fluid flow behaviors were simulated using the standard k- $\varepsilon$ turbulence model, under Ansys-Fluent software. The simulation results showed that, at a certain value of inlet aspect ratio $\left(R_{I A}\right)$ and initial tangential intensity $\left(I_{I T}\right)$, especially for high $I_{I T}$ the recirculation flow phenomenon was clearly observed in the center of the burner cylinder which closely resembles a tornado-tail. The indication of existence recirculation flow was also found from the experiment results. The study also exhibited that the results of simulated static pressure drop were closely approaching the experiment results, particularly for $I_{I T}$ values $\leq 4.3$. The mean deviation of static pressure between the simulation and the experiment results, for a varied range of $R_{I A}$ and $I_{T T}$, was about $15 \%$. From the results above, it was obvious that fluid flow behaviors (recirculation flow and static pressure) in the proposed cyclone burner are greatly influenced by the $R_{I A}$ and $I_{I T}$ values, where the $I_{I T}$ effect was more significant compared to the $R_{I A}$. This study also suggests that, the standard $k-\varepsilon$ turbulence model could be relied upon to well predict the behaviors of fluid flow in the proposed cyclone burner, at low to moderate swirl intensities.

Keywords: Cyclone burner, Initial tangential intensity, Inlet aspect ratio, Paper slice dynamic, Recirculation flow, Static pressure, Standard k- $\varepsilon$ turbulence model, Tornado-tail

\section{INTRODUCTION}

Recirculation flow from a furnace to a burner can sustain flame stability in the burner, especially for the solid-fueled burner. It brings hot combustion gas from 
the furnace to the burner; therefore, burner temperature is always high and capable of heating and burning incoming fuel (Al Abdeli and Masri 2015).

Several researchers have studied the formation of recirculation flow in any chamber. They revealed that the recirculation flow trigger is the swirl flow. The effect of chamber geometry on the swirl flow behaviors has been studied by Bourgouin et al. (2013), Arnao, et al. (2015), and Ziqiang et al. (2016). The effect of chamber operating conditions on swirl flow behaviors has been studied by Nemoda (2005) and Pasymi et al. (2018). They state that, in general, recirculation flow is formed at moderate to high swirl intensities.

Apart from affecting recirculation flow formation, swirl flow also influences other fluid dynamics characteristics such as mixing intensity, residence time, pressure drop, and particle distribution (Arnao et al. 2015, Pasymi et al. 2017). The use of swirl flow introduces a challenge due to its potential of increasing static pressure in the burner (Aydin et al. 2014, Gawali and Bhambere 2015).

From the perspective of fluid dynamics, static pressure serves as an obstacle to the fluid flow. The higher the static pressure, the greater the power required to drain the air and fuel into the boiler furnace, resulting in a higher burner operating costs. A compromise of the swirl intensity value must be found where the recirculation flow can be formed while the pressure drop can be obtained as low as possible.

Although there have been many studies on swirl flow behaviors by researchers, supplementary studies still need to be conducted to develop new types of the burner. One of the potential new burners is a light biomass burner. Light biomass has great potential to be used as boiler fuel in the future. The biomass's physical and chemical characteristics are significantly different from coal (Baxter et al. 2005, Vassilev et al. 2015). As a result, the design of geometry and operating conditions of this burner type requires separate studies.

The proposed cyclone burner design in this study is dedicated to light biomass. The geometric design consisted of a cylindrical tube with an axial inlet and a tangential injection inlet. The cross-section shape of the axial inlet is a circle, and the cross-section shape of the tangential inlet is rectangular, as shown in Figure 1.

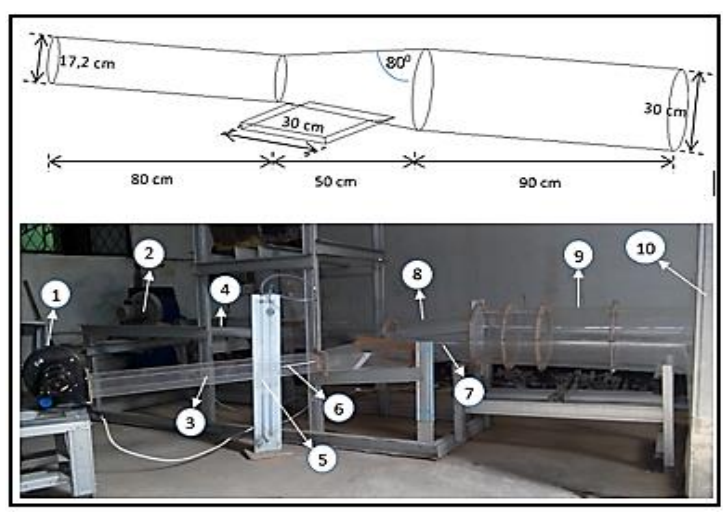

Annotation:

$$
\begin{array}{ll}
1=\text { tangential blower } & 6=\text { pitot tube } \\
2=\text { axial blower } & 7=\text { tangential inlet } \\
3=\text { tangential inflow } & 8=\text { frustum } \\
4=\text { axial inflow } & 9=\text { burner cylinder } \\
5=\text { U-shaped manometer } & 10=\text { furnace box }
\end{array}
$$

Fig. 1: Burner geometry and experimental equipment set-up

This research aims to study the effects of tangential inlet thickness and velocity on the formation of recirculation flow and pressure drop profile in the proposed 
cyclone burner. This study is also intended to evaluate whether the standard $\mathrm{k}-\varepsilon$ turbulent model can predict the swirl flow behaviors satisfactorily in the burner.

\section{INVESTIGATION METHODOLOGY}

The method used in this study was a combination of experimental and numerical methods. The experimental method was carried out under limited conditions and the results were used to validate the simulation results. Meanwhile, the numerical method was applied widely until comprehensive data and information were obtained.

\section{Experimental Set-Up}

The experiment to determine the recirculation flow pattern and static pressure profile was conducted in a cyclone burner made of transparent material (acrylic). The burner geometry and experimental equipment set-up are given in Figure 1.

In this experiment, the recirculation flow pattern in the cyclone burner was observed through paper slices dynamic. Then, it was visualized using a camera. The paper used was a bright color wax paper. This type of paper was chosen due to its low specific gravity and susceptibility toward water vapor. The paper slices were $10 \mathrm{~cm}$ in length, $0.5 \mathrm{~cm}$ in wide, and 0.002 $\mathrm{cm}$ in thickness, with an average weight of $0.015 \mathrm{gr}$ per slice. The paper slices were stick on a long thread and installed along the $y$-axis of the burner at a specific $z$ position. The paper stripes were assembled in a horizontal position, as shown in Figure 2 (a), to avoid the gravitational effect at a particular distance $(\mathrm{z})$,

Meanwhile, static pressure was measured using a U-shaped tube manometer. The static pressure at each end of the burner cylinder was extracted through $\pm 2 \mathrm{~mm}$-diameter-hole, at $\mathrm{z}=$ 1.31 and $z=2.19 \mathrm{~m}$. Then, both holes were connected to U-tube filled with water. The water height difference in $\mathrm{U}$ tube was converted to show the static pressure difference in the Pascal unit. The set-up of static pressure measurement can be seen in Figure 2 (b).

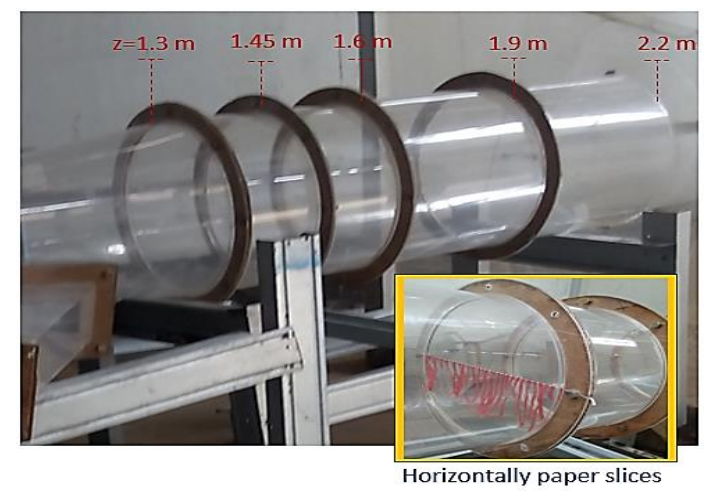

(a)

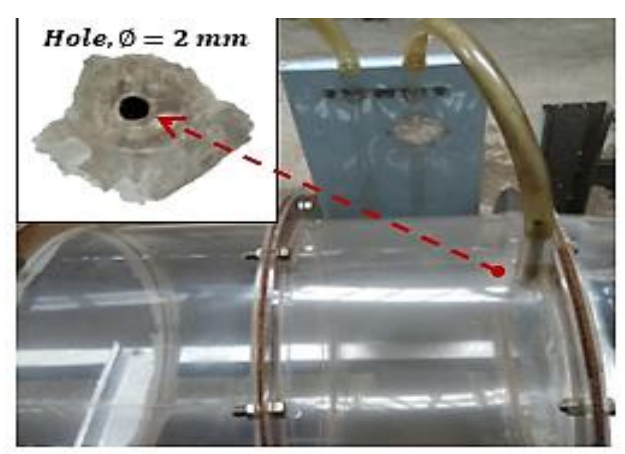

(b)

Fig. 2: Experimental equipment set-up; (a) Paper slices dynamic determination; (b) Static pressure meassurement

Air velocity, both through axial and tangential inlets, was determined using a pitot tube. Variation of airflow rate in each 
inlet was arranged by adjusting the blower-opening size.

\section{Simulation Techniques}

Numerically, fluid dynamics in this study was simulated using the standard k$\varepsilon$ turbulence model. Previous researchers have reported that this model can describe flow well, particularly for low swirl flow intensity (Nemoda et al. 2005, Vazquez 2012, Reis et al. 2014, Pasymi et al. 2017). Eqs. (1) to (4) are partial differential equations used in the standard k- $\varepsilon$ turbulence model (Bindar 2017).

$\frac{\partial \rho}{\partial t}=\frac{\partial \rho \bar{u}_{x}}{\partial x}+\frac{\partial \rho \bar{u}_{y}}{\partial y}+\frac{\partial \rho \bar{u}_{z}}{\partial z}$

$\frac{\partial \rho \bar{u}_{i}}{\partial t}+\sum_{j=x}^{y, z} \rho \bar{u}_{j} \frac{\partial \bar{u}_{i}}{\partial j}=-\frac{\partial \bar{p}}{\partial i}+$

$\sum_{j=x}^{y, z} \frac{\partial}{\partial j}\left[\left(\mu+\mu_{t}\right) \frac{\partial \bar{u}_{i}}{\partial j}\right]+\rho g_{i}$

where $i=x, y, z$

$\rho \frac{\partial k}{\partial t}+\sum_{j=x}^{y, z} \rho \bar{u}_{j} \frac{\partial k}{\partial j}=\sum_{j=x}^{y, z} \frac{\partial}{\partial j}\left[\frac{\mu_{\mathrm{eff}}}{\sigma_{\mathrm{k}}} \frac{\partial k}{\partial j}\right]+$

$G_{\mathrm{k}}-\rho \varepsilon$

$\rho \frac{\partial \varepsilon}{\partial t}+\sum_{j=x}^{y, z} \rho \bar{u}_{j} \frac{\partial \varepsilon}{\partial j}=\sum_{j=x}^{y, z} \frac{\partial}{\partial j}\left[\frac{\mu_{\mathrm{eff}}}{\sigma_{\varepsilon}} \frac{\partial \varepsilon}{\partial j}\right]$

$+C_{\varepsilon 1} \frac{\varepsilon}{k} G_{k}-C_{\varepsilon 2} \rho \frac{\varepsilon^{2}}{k}$

Variables $x, y$, and $z$ on the equations are the direction components of the Cartesian coordinate, while $\bar{u}_{x}, \bar{u}_{y}$, and $\bar{u}_{z}$ are the average velocity for each direction component. Variable $k$ is the specific turbulent kinetic energy, and $\varepsilon$ is the dissipation rate of the specific turbulent kinetic energy.

The turbulent viscosity $\left(\mu_{\mathrm{t}}\right)$ is formulated by the semi-empirical equation shown in Eq. (5). Meanwhile, $G_{k}$ is the production rate of specific turbulent kinetic energy and given by Eq. (6). Parameters $C_{\mu}, C_{\varepsilon 1}, C_{\varepsilon 2}, \sigma_{\mathrm{k}}$, and $\sigma_{\varepsilon}$ are the empirical constants.

$\mu_{t}=C_{\mu} \rho\left(k^{2} / \varepsilon\right)$

$G_{\mathrm{k}}=2 \mu_{\mathrm{t}} \sum_{j=x}^{y, z}\left(\frac{\partial \bar{u}_{j}}{\partial j}\right)^{2}+\mu_{\mathrm{t}}\left[\left(\frac{\partial \bar{u}_{\mathrm{x}}}{\partial y}+\right.\right.$

$\left.\left.\frac{\partial \bar{u}_{\mathrm{y}}}{\partial x}\right)^{2}+\left(\frac{\partial \bar{u}_{\mathrm{x}}}{\partial z}+\frac{\partial \bar{u}_{\mathrm{z}}}{\partial x}\right)^{2}+\left(\frac{\partial \bar{u}_{\mathrm{y}}}{\partial z}+\frac{\partial \bar{u}_{\mathrm{z}}}{\partial y}\right)^{2}\right]$

The simulation was performed in a steady-state condition using Ansys-Fluent software. The wall boundary condition was built based on the assumption of no split condition. Therefore, all turbulent variables $\left(\bar{p}, \bar{u}_{x}, \bar{u}_{y,} \bar{u}_{z}, k\right.$, and $\left.\varepsilon\right)$ on the burner wall are zero. Meanwhile, the turbulent variable's value near the wall (at the log layer) is determined by a standard wall function.

\section{Research Variables}

There are two research variables investigated here. Those are tangential inlet thickness and tangential inlet velocity. Tangential inlet thickness is expressed in the form of inlet aspect ratio $\left(R_{1 A}\right)$, which is the ratio between the width to the thickness of the tangential inlet crosssection, as given in Eq. (7).

$$
R_{I A}=\frac{l}{d}
$$

Variation in $R_{I A}$ values was arranged by keeping the width value constant while varying tangential inlet thickness. The correspondent width was $30 \mathrm{~cm}$, while the thickness values were 2,3 , and $4.5 \mathrm{~cm}$. As a result, the variation of $R_{I A}$ used was 15 , 10 , and 6.7 .

Meanwhile, tangential velocity is expressed as initial tangential intensity $\left(\mathrm{I}_{\mathrm{IT}}\right)$. 
Initial tangential intensity is calculated based on the Eq. (8) (Chen et al. 1999).

$$
I_{i t}=\left(\frac{\dot{m}_{t}}{\dot{m}_{c}}\right)^{2}\left(\frac{A_{c}}{A_{t}}\right)^{2}
$$

Variable $A_{c}$ is the cross-sectional area of the burner cylinder and $A_{t}$ is the crosssectional area of the tangential inlet. Meanwhile, $\dot{m}_{c}$ and $\dot{m}_{t}$ are the mass flow rate through the burner cylinder and tangential inlet, respectively. The higher the $I_{T}$, the higher the swirl flow intensity would be, and vice versa. In this experiment, $I_{I_{T}}$ values were varied between $2.5-5.6$.

\section{RESULTS AND DISCUSSION}

\section{The Effect of $I_{I T}$ on Recirculation flow Pattern for Various Values of $\mathbf{R}_{\mathbf{I A}}$}

The effect of $I_{I T}$ on recirculation flow is discussed in 3 groups, namely for $R_{I A}$ values of 15, 10, and 6.7. Each group will simultaneously discuss research results, experimentally and numerically.

\section{Burner with $R_{I A}=15$}

The simulation result showed that for $\mathrm{I}_{\mathrm{T}}=4.6$, recirculation flow was formed in the burner. The recirculation flow occurred in the middle of the burner, which stretched along with the burner cylinder. It flowed continuously as a vortex that resembled a tornado-tail, as shown in Figure 3 (a). A similar phenomenon also arose for $\mathrm{I}_{\mathrm{IT}}=2.5$, however, shorter recirculation flow penetration was formed for this $I_{I T}$ value. It only occurred along the 2/5-end of the burner cylinder, as shown in Figure 3 (b).

The profile of axial velocity vector, as depicted in Figure 4 (a), shows an indication of recirculation flow in the center of the burner. The evidence of recirculation flow existence was shown by the negative value of the axial velocity vector (pointed to the left).

The existence of that particular recirculation flow was later evaluated experimentally through paper slices dynamic experiment, at position $z=1.45$ $\mathrm{m}$. For $\mathrm{I}_{\mathrm{T}}=4.6$, there was an indication of recirculation flow formed in the middle of the burner. It can be observed from the presence of paper slices in the middle of the burner flowing upside down, as shown on the left of Figure 4 (b). This indicates that there is a match between the simulation results with the experimental ones.

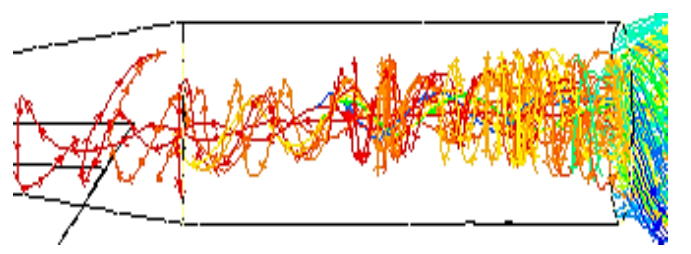

(a)

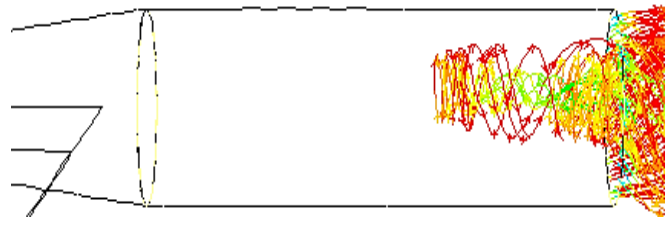

(b)

Fig. 3: Recirculation flow patterns for (a) $I_{\mathrm{T}}=$ 4.6 and (b) $I_{I_{T}}=2.5$ at $R_{\mathrm{IA}}=15$

The comparison between flow pathlines from experiment and simulation results, which was extracted at $z=1.45 \mathrm{~m}$, can be seen in Figure 4 (b). The figure showed that the flow pathlines from the simulation result, with the standard $k-\varepsilon$ turbulence model, was almost identical to the paper slices dynamic experiment result. 
For lower velocity $\left(I_{\mid T}=2.5\right)$, the experiment result indicated the formation of recirculation flow at $\mathrm{z}=1.45 \mathrm{~m}$, as shown in Figure 5 (b). The recirculation flow had smaller intensity compared to the previous one. This result seemed to contradict the result in Figure 3 (b), which showed that no recirculation flow was formed at the $z$ position. This result could be explained from the visualization of the axial velocity vector, as depicted in Figure 5 (a). The axial velocity vector distribution, at the zx plane, showed two indications of recirculation flows located at the 1/4-start and $2 / 5$-end of the burner cylinder.

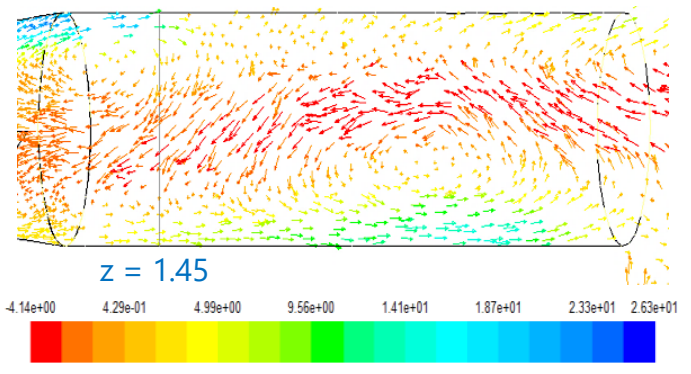

(a)

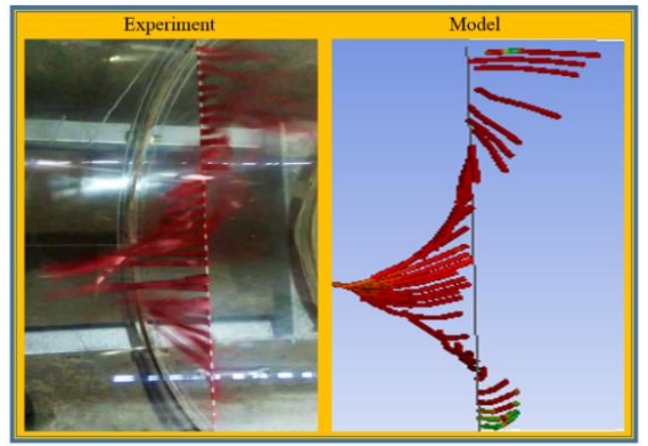

(b)

Fig. 4: (a) Axial velocity profiles and (b) flow pathlines at $z=1.45 \mathrm{~m}$ at $\mathrm{I}_{\mathrm{IT}}=4.6$

The recirculation flow occurred in the first $1 / 4$ length of the burner cylinder was called internal recirculation flow. On the other hand, recirculation flow formed in the 2/5-end of burner cylinder length was called external recirculation flow. The later was responsible for sustaining flame stability because it would bring hot flue gas from the furnace into the burner to maintain burner temperature high (AlAbdeli and Masri 2015).

Figure 5 (a) shows that at $z=1.45 \mathrm{~m}$, some axial velocity vectors were directed to the left. It indicates the formation of recirculation flow at that particular position in the form of internal recirculation flow. That recirculation flow phenomenon was the one that was recorded by paper slices dynamic experiment. The simulation result with a fluid release line at $z=1.45 \mathrm{~m}$ also revealed a formation of low-intensity recirculation flow. The comparison of recirculation flow patterns of simulation and experiment results, at $\mathrm{z}=1.45 \mathrm{~m}$, were depicted in Figure 5 (b). It is seen that both patterns showed a high level of adequate similarity.

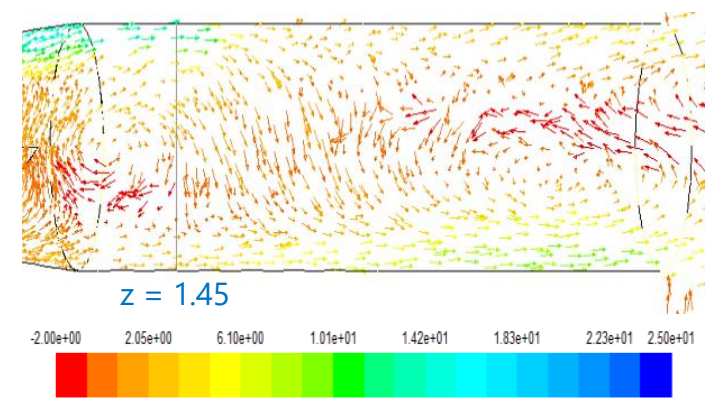

(a)

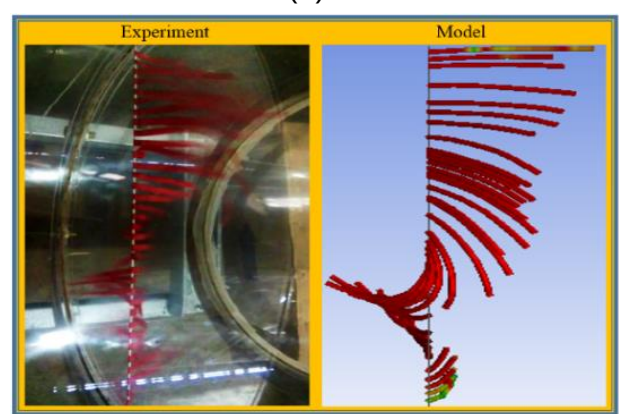

(b)

Fig. 5: (a) Axial velocity profiles and (b) flow pathlines at $z=1.45 \mathrm{~m}$ at $R_{\mathrm{IA}}=15$ and $\mathrm{I}_{\mathrm{IT}}=2.5$ 


\section{Burner with $R_{I A}=10$}

Numerically, at $\mathrm{I}_{\mathrm{TT}}=5.3$, recirculation flow with a tornado-tail like a pattern was found to penetrate along the burner cylinder, as depicted in Figure 6 (a). While, at a lower $I_{I T}$ value of 2.8 , the recirculation flow pattern only penetrated along the $1 / 3$-end of the burner cylinder, as shown in Figure 6 (b).

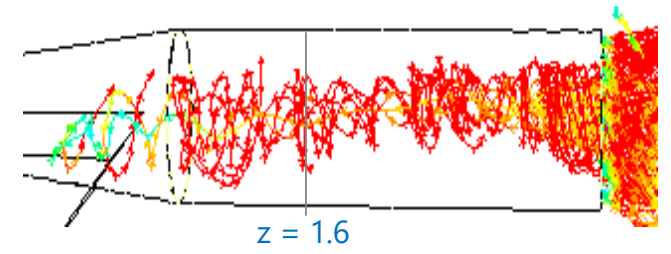

(a)

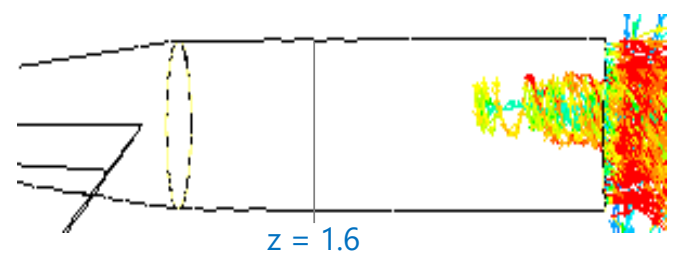

(b)

Fig. 6: Recirculation flow patterns for (a) $I_{I T}=$ 5.3 and (b) $I_{I_{T}}=2.8$ at $R_{\mathrm{IA}}=10$

Experimentally, the existence of recirculation flow was evaluated at $z=1.6$ $\mathrm{m}$. For IIT $=5.3$, the indication of recirculation flow was found, while for IIT $=2.8$, there was no recirculation flow. These findings were in line with the simulation results, as in Figure 6.

Figure 7 (a) indicates the existence of recirculation flow at $z=1.6 \mathrm{~m}$ and $\mathrm{I}_{\mathrm{T}}=5.3$, experimentally. While Figure 7 (b) depicts no recirculation flow indication at lower $I_{\text {IT }}$ value (2.8).

\section{Burner with $R_{I A}=6,67$}

The simulation result, for $\mathrm{I}_{\mathrm{T}}=5.3$, indicated the formation of recirculation flow that penetrated along 2/3-end of the burner cylinder, as shown in Figure 8 (a). It was supported by the experiment result that showed the indication of recirculation flow at $z=1.90 \mathrm{~m}$. The comparison of paper slices dynamic visualization and the simulation result is given in Figure 9 (a).

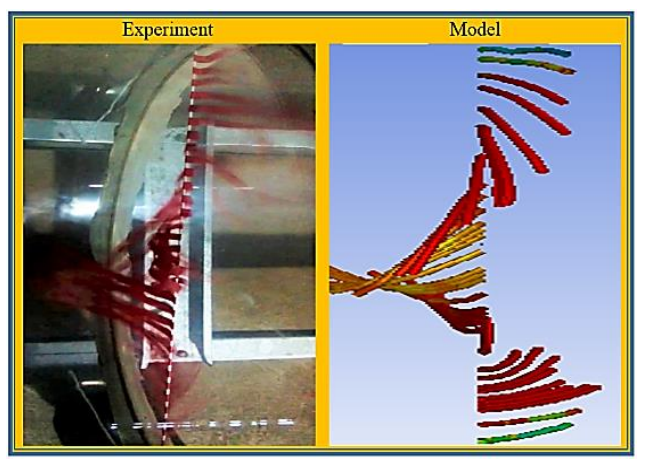

(a)

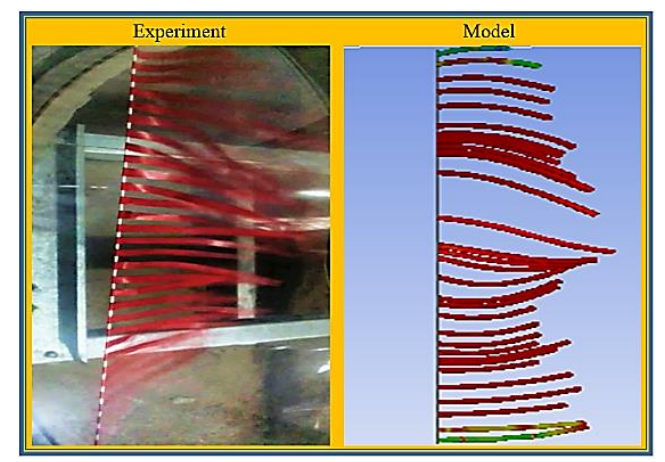

(b)

Fig. 7: Comparison of flow pathlines from experiment and simulation for (a) $\mathrm{I}_{\mathrm{T}}=5.3$ and (b) $I_{\mathrm{IT}}=2.8$ at $R_{\mathrm{Al}}=10$

For $I_{I T}=2.9$, the simulation result did not show any recirculation flow indication along with the burner cylinder, as seen in Figure 8 (b). The absence of recirculation flow indication under this condition is also shown by the result of the paper slices' dynamic experiment at $\mathrm{z}=1.9 \mathrm{~m}$, as shown in Figure 9 (b).

From various operating conditions above, it was found that recirculation flow patterns of simulation results were similar with experiment results of paper slices dynamic. It may be said that the standard 
$\mathrm{k}-\varepsilon$ turbulence model was able to predict well the existence of a recirculation flow pattern in a cyclone burner. Simulation results also showed that the recirculation flow pattern in the burner was greatly influenced by tangential velocity $\left(\mathrm{I}_{\mathrm{T}}\right)$ and tangential inlet thickness $\left(R_{\mid A}\right)$. It is consistent with the findings of Nemoda and Bourgoin (Nemoda et al. 2005, Bourgouin et al. 2015).

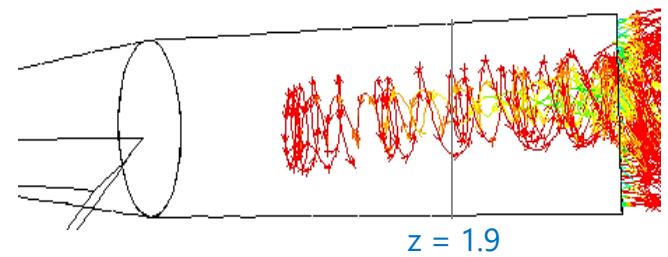

(a)

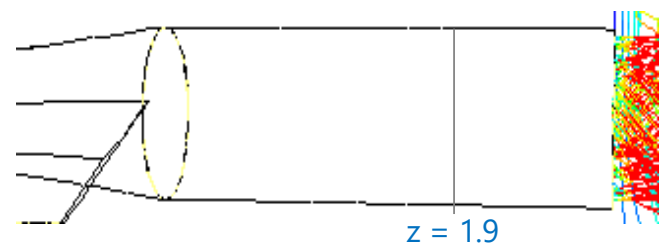

(b)

Fig. 8: Recirculation flow patterns for (a) $I_{\mathrm{IT}}=$ 5.3 and (b) $I_{\mathrm{IT}}=2.9$ at $\mathrm{R}_{\mathrm{IA}}=6.67$

The Effect of $R_{I A}$ and $I_{I T}$ to Static Pressure

Static pressure difference along a burner cylinder is caused by the kinetic energy dissipation rate (epsilon) resulting from friction loss. Kinetic energy dissipation dominantly occurs in the area near the burner's wall. Therefore, static pressure measurement is conducted in that particular area.

\section{The Effect of $I_{I T}$ to Static Pressure}

Experiment results showed that the higher the $I_{T}$, the bigger the difference in static pressure along the burner cylinder would be. A similar result was achieved from the simulation using the standard $k-\varepsilon$ turbulence model. The mean deviation of the static pressure from simulation results compared to experimental results for $R_{\mathrm{IA}}$ 15,10 and 6.7 were 10,14, and 20\%, respectively. The comparison of static pressure drop profile for several $R_{I A}$ and $I_{I T}$ values is shown in Fig. 10. The difference between the simulation results to the experiment results increased with the rise of $\mathrm{I}_{\mathrm{T}}$. For $\mathrm{I}_{\mathrm{TT}} \leq 4.3$, the deviation was under $20 \%$. It is similar to previous studies that state that, for low swirl intensity, the standard $k-\varepsilon$ turbulence model can satisfactorily model swirl flows well (Nemoda et al. 2005, Pasymi et al. 2017, Vazquez 2012).

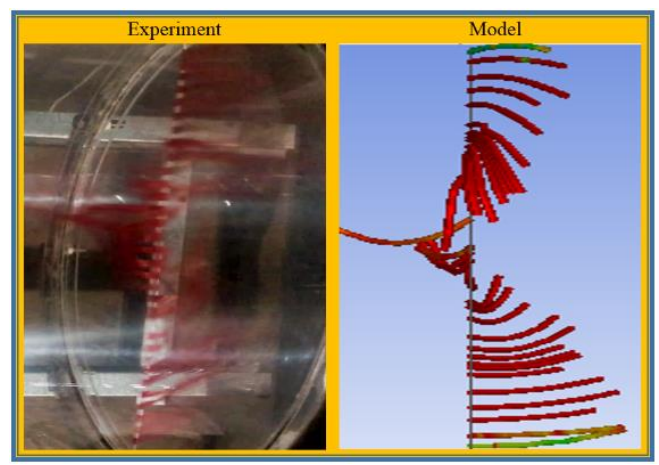

(a)

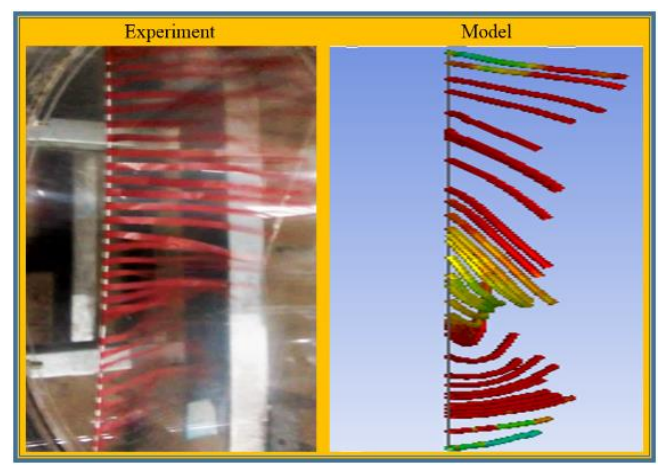

(b)

Fig. 9: Comparison of flow pathlines of experiment and simulation for (a) $I_{T T}=5.3$ and (b) $I_{I T}=2.9$ at $R_{A I}=6.67$

For $I_{I T}>4.3$, the difference between simulation results and experiment results 
were higher. It happened because, for high values of $I_{I T}$, the swirl flow tends to be nonisotropic, with different turbulent strength penetrating to all direction components (Jakirlic et al. 2002). Meanwhile, the standard $k-\varepsilon$ turbulence model is built based on the isotropic turbulent assumption, where turbulent velocity is considered uniform in every direction. It is why, the isotropic assumption is difficult to accept for turbulent swirl flow, particularly for high swirl intensity.

The dependency of the pressure drop to the tangential velocity $\left(I_{I T}\right)$ can be explained as follow; (1) for high values of $\mathrm{I}_{\mathrm{T}}$, the tangential velocity in the inlet burner would be high, (2) on the contrary, the static pressure on that position would be low, (3) due to kinetic energy dissipation from friction loss along with the burner cylinder, the tangential velocity toward the burner outlet would decrease, (4) on the other hands, the kinetic energy dissipation rate (epsilon) and the pressure drop along the burner cylinder would grow. Therefore, the higher the value of $I_{I T}$, the greater the pressure drop along the burner cylinder would be, and vice versa.

\section{The Effect of $R_{I A}$ to Static Pressure}

Both experiment and simulation results indicated that the static pressure loss in the burner was directionally proportional to the inlet aspect ratio $\left(R_{I A}\right)$. The higher the value of $R_{I A}$, the greater static pressure difference in the burner would be. The comparison between simulation and experiment result, for $\mathrm{I}_{\mathrm{IT}}=3.4$, is depicted in Figure 11. On average, the pressure drop from the simulation result deviated \pm $27 \%$ from the experiment ones.

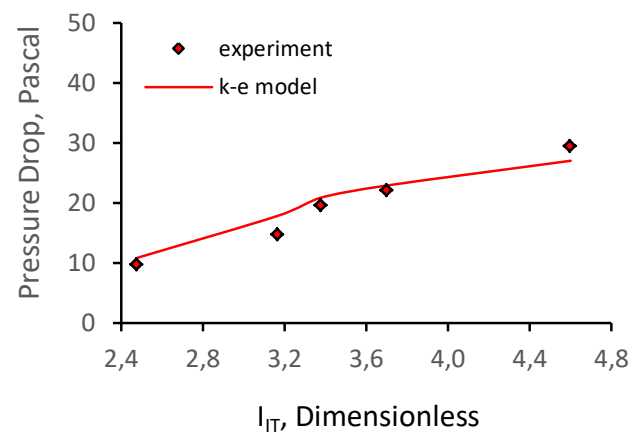

(a)

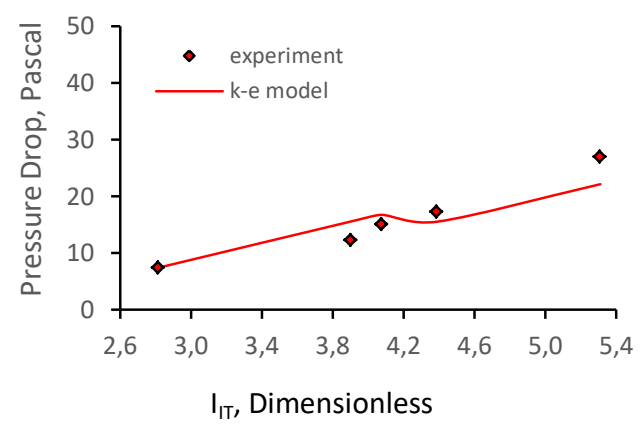

(b)

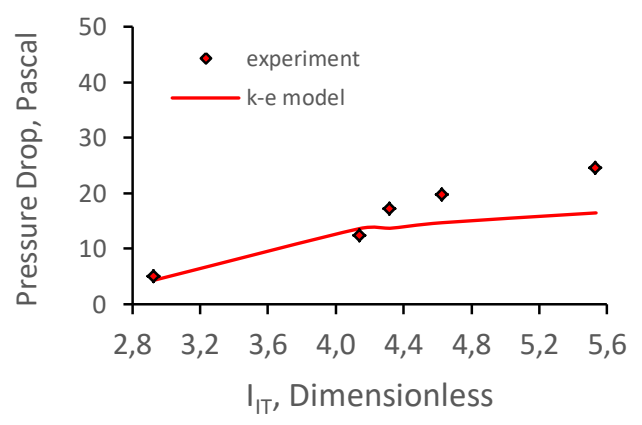

(c)

Fig. 10: Profiles of static pressure drop in the burner for various $I_{I T}$ values at $R_{I A}=15$, (b) $R_{I A}$ $=10$, and (c) $R_{\mathrm{IA}}=6.67$

The difference in $R_{I A}$ would affect the tangential inlet cross-sectional area. The thinner the tangential inlet thickness (the bigger the $\mathrm{R}_{\mathrm{IA}}$ ), the smaller the crosssectional area of tangential inlet would be, and the higher the tangential velocity would be. It leads to the higher kinetic energy dissipation rate (epsilon) and the pressure drop would be. As a result, the bigger $R_{I A}$ would result in a bigger pressure drop. 


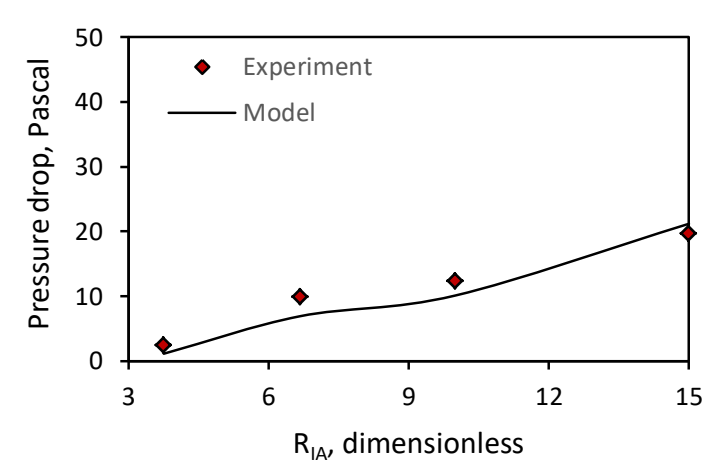

Fig. 11: Profiles of static pressure drop in the burner for various $R_{\mathrm{IA}}$ values

\section{CONCLUSIONS}

Experimental and simulation results revealed that the recirculation flow phenomenon was greatly influenced by initial tangential intensity $\left(I_{T T}\right)$ and inlet aspect ratio $\left(R_{I A}\right)$. The higher the $I_{I T}$, the higher the swirl flow intensity, and the greater the potential for recirculation flow to form. The formation of the recirculation flow is also directly proportional to the $R_{I A}$. The recirculation flow patterns formed in the burner closely resembled a tornado tail. The same trend also occurs to the pressure drop; the higher the $I_{I T}$ and $R_{I A}$, the greater the pressure drop produced and vice versa.

From all experiments and simulations carried out, there was a match between both results for the phenomenon of recirculation flow and the pressure drop profile. The recirculation flow patterns from simulation results were highly similar to the results of the experiment of paper slices dynamic. Furthermore, the mean deviation of pressure drop from simulation and experiment ones, for a varied range of $R_{I A}$ and $I_{I T}$, was relatively low (about $15 \%$ ). It may almost be stated that the standard $\mathrm{k}-\varepsilon$ turbulence model could predict the recirculation flow pattern and static pressure profile in the proposed cyclone burner satisfactorily well, particularly for $I_{T T}$ $\leq 4.3$.

\section{ACKNOWLEDGMENT}

We would like to thank the expertise group of research directorates of ITB for the funding support provided to the implementation of this research through the $\mathrm{P} 3 \mathrm{MI}$ scheme.

\section{NOMENCLATURE}

$$
\begin{array}{lll}
d & : \text { tangential inlet thickness }[\mathrm{m}] \\
g & : \text { acceleration gravity }\left[\mathrm{m} \mathrm{s}^{-2}\right] \\
l & : \text { Tangential inlet width [m] } \\
\bar{p} & : \text { mean static pressure [Pascal] } \\
\rho & : \text { density }\left[\mathrm{kg} \mathrm{m}{ }^{-3}\right] \\
\mu & : \text { dynamics viscosity }\left[\mathrm{kg} \mathrm{m}^{-1} \mathrm{~s}^{-1}\right] \\
\mu_{e f f} & : \text { effective viscosity }\left[\mathrm{kg} \mathrm{m}^{-1} \mathrm{~s}^{-1}\right] \\
t & : \text { time }[\mathrm{s}]
\end{array}
$$

\section{REFERENCES}

1. Al-Abdeli, Y. M., and Masri, A. R. (2015). "Review of laboratory swirl burners and experiments for model validation," Exp. Therm. Fluid Sci., 69, 178-196.

2. Arnao, J. H. S., Ferreira, D. J. O., Santos, C. G., Alvarez, J. E., Rangel, L. P., and Park, S. W. (2015). "The influence of swirl burner geometry on the sugarcane bagasse injection and burning," International Journal of Mechanical, Aerospace, Industrial, Mechatronic and Manufacturing Engineering, 9, 798-801. 
3. Aydin, O., Avci, M., Markal, B., and Yazici, Y. (2014). "An experimental study on the decaying swirl flow in a tube," Int. Commun. Heat Mass, 55, $22-$ 28.

4. Baxter, L., Ip, L., Lu, H., and Tree, D. (2005). "Distinguishing biomass combustion characteristics and their implications for sustainable energy," The $5^{\text {th }}$ Asia Pacific Conference on Combustion, University of Adelaide, Australia.

5. Bindar, Y. (2017). Rekayasa komputasi aliran turbulen multidimensi, $1^{\text {st }}$ ed., ITB Press, Bandung, Indonesia.

6. Bourgouin, J. F., Moeck, J., Durox, D., Schuller, T., and Candel, S. (2013). "Sensitivity of swirling flows to small changes in the swirler geometry," $C R$ Mecanique, 341, 211-219.

7. Chen, J., Haynes, B. S., and Fletcher, D. F. A. (1999). "Numerical and experimental study of tangentially injected swirling pipe flows," The $2^{\text {nd }}$ International Conference on CFD in the Minerals and Process Industries CSIRO, Melbourne, Australia, 485 - 490.

8. Gawali, S. S., and Bhambere, M. B. (2015). "Computational fluid dynamics approach for predictions of cyclone separator pressure drop," IJMERR, 4 (1), 374-377.

9. Jakirlic, S., Hanjalic, K., and Tropea, C. (2002). "Modelling rotating and swirling turbulent flows: A perpetual challenge," AIAA J, 40, 1984-1996.

10. Nemoda, S., Bakic, V., Oka, S., Zivkovic, G., and Crnomarkavic, N. (2005). "Experimental and numerical investigation of gaseous fuel combustion in swirl chamber," Int. J.
Heat Mass Tran., 48, 4623-4632.

11. Pasymi, Budhi, Y. W., and Bindar, Y. (2017). "Effect of initial tangential intensity on the fluid dynamic characteristics in tangential burner," MATEC Web Conf., 101, 1-6.

12. Pasymi, Budhi, Y. W., and Bindar, Y. (2018). “Three dimensional cyclonic turbulent flow structures at various geometries, inlet-outlet orientations, and operating conditions," J. Mech. Eng. Sci., 12 (4), 4300-4328.

13. Reis, L. C. B. S., Carvalho, J. A. Jr., Nascimento, M. A. R., Rodrigues, L. O., Dias, F. L. G., and Sobrinho, P. M. (2014). "Numerical modeling of flow through an industrial burner orifice," Appl. Therm. Eng., 67, 201-213.

14. Vassilev, S. V., Vassileva, C. G., and Vassilev, V. S. (2015). "Advantages and disadvantages of composition and properties of biomass in comparison with coal: An overview," Fuel, 158, 330350.

15. Vazquez, J. A. R. (2012). A computational fluid dynamics investigation of turbulent swirling burner, Thesis, University of Zaragoza, Spain.

16. Ziqiang, L. V., Guangqiang, L., and Yingjie, L. (2016). "Optimization Study on Bias Angle of a Swirl Burner with Tangential Inlet Air," International Journal of Smart Home, 10, 171-180. 